\begin{tabular}{|c|c|c|}
\hline \multirow{3}{*}{$\begin{array}{r}\text { Case Reports in } \\
\text { Gastroenterology }\end{array}$} & \multirow{2}{*}{\multicolumn{2}{|c|}{ Case Rep Gastroenterol 2016;10:17-23 }} \\
\hline & & \\
\hline & DOI: $10.1159 / 000443267$ & $\begin{array}{l}\text { (c) } 2016 \text { The Author(s) } \\
\text { Published by S. Karger AG, Basel } \\
\text { www.karger.com/crg }\end{array}$ \\
\hline & $\begin{array}{l}\text { This article is licensed ur } \\
\text { International License (CC } \\
\text { Usage and distribution for }\end{array}$ & $\begin{array}{l}\text { nons Attribution-NonCommercial } 4.0 \\
\text { ger.com/Services/OpenAccessLicense). } \\
\text { uires written permission. }\end{array}$ \\
\hline
\end{tabular}

\title{
Safety of Regular-Dose Imatinib Therapy in Patients with Gastrointestinal Stromal Tumors Undergoing Dialysis
}

\author{
Ryota Niikura $^{\mathrm{a}}$ Takako Serizawa $^{\mathrm{a}}$ Atsuo Yamada ${ }^{\mathrm{a}}$ Shuntaro Yoshida ${ }^{\mathrm{b}}$ \\ Mariko Tanaka ${ }^{c}$ Yoshihiro Hirata ${ }^{a}$ Kazuhiko Koike ${ }^{a}$ \\ a Department of Gastroenterology, Graduate School of Medicine, The University of Tokyo, \\ Tokyo, Japan; ${ }^{b}$ Endoscopy and Endoscopic Surgery, The University of Tokyo Hospital, \\ Tokyo, Japan; ' Department of Pathology, Graduate School of Medicine, The University of \\ Tokyo, Tokyo, Japan
}

\section{Keywords}

Imatinib · Hemodialysis · Gastrointestinal stromal tumors

\begin{abstract}
The number of cancer patients undergoing dialysis has been increasing, and the number of these patients on chemotherapy is also increasing. Imatinib is an effective and safe therapy for KIT-positive gastrointestinal stromal tumors (GIST), but the efficacy and safety of imatinib in dialysis patients remain unclear. Because clinical trials have not been conducted in this population, more investigations are required. We report on a 75-year-old Japanese man undergoing dialysis who presented with massive tarry stool from a duodenal GIST. The duodenal GIST was $14 \mathrm{~cm}$ in diameter with multiple liver and bone metastases. The patient underwent an urgent pancreaticoduodenectomy to achieve hemostasis. After surgery, he was administered imatinib $400 \mathrm{mg} /$ day. No severe adverse event including myelosuppression, congestive heart failure, liver functional impairment, intestinal pneumonia, or Steven-Johnson syndrome occurred, and the liver metastasis remained stable for 4 months. During chemotherapy, hemodialysis continued three times per week without adverse events. We suggest that regular-dose imatinib is an effective and safe treatment in patients with GIST undergo-
\end{abstract}


C 2016 The Author(s). Published by S. Karger AG, Basel www.karger.com/crg

Niikura et al.: Safety of Regular-Dose Imatinib Therapy in Patients with Gastrointestina Stromal Tumors Undergoing Dialysis

ing dialysis. In addition, we present a literature review of the effectiveness and safety of imatinib treatment in dialysis patients.

\section{Introduction}

Approximately $6 \%$ of patients undergoing dialysis have malignancies [1], and the number of these patients undergoing chemotherapy continues to increase. Chemotherapy in dialysis patients is challenging because excretion of the drug differs between dialysis and non-dialysis patients. Drugs that are excreted by dialysis may show reduced efficacy, while drugs that are not excreted may cause adverse events.

Imatinib is an effective and safe therapy for KIT-positive gastrointestinal stromal tumors (GIST) [2-5]. However, the efficacy and safety of imatinib treatment in dialysis patients remain unclear because clinical trials have not been conducted in this population. Further information is required on dialysis patients treated with imatinib.

We report a patient with duodenal GIST undergoing dialysis who was treated with regular-dose imatinib and remained stable with no adverse events for 4 months. We also present a literature review of the efficacy and safety of imatinib treatment in patients with GIST undergoing dialysis.

\section{Case Presentation}

In a 75-year-old Japanese man, a large duodenal tumor was identified on computed tomography (CT) in 2008 and was suspected as GIST on endoscopic ultrasonography. However, the patient refused further investigation and underwent a follow-up visit. He also had chronic kidney disease, due to type 2 diabetes, and began a course of hemodialysis three times weekly in 2014.

A large-volume and painless tarry stool with hemorrhagic shock occurred in April 2014. A complete blood count showed a hemoglobin level of $6.3 \mathrm{~g} / \mathrm{dl}$, and the patient required transfusion of 32 units of packed red blood cells to recover a general condition. Contrast agent-enhanced CT scans revealed a duodenal tumor $14 \mathrm{~cm}$ in diameter, with multiple liver and bone metastases. The patient underwent an urgent upper endoscopy, which showed a $3.5-\mathrm{cm}$ submucosal tumor with stigmata of recent hemorrhage in the bulb of the duodenum. Endoscopic hemostasis was not conducted due to the large exposed vessel, and an urgent pancreaticoduodenectomy was performed to achieve hemostasis. The resected tumor showed a GIST composed of spindle-shaped cells with positive staining for KIT and CD34 and negative staining for S-100; the mitotic count was 12 per 50 high-power fields, and the MIB-1 labeling index was 10\% (fig. 1).

After surgery, the patient was treated with imatinib at a dose of $400 \mathrm{mg}$ daily (orally). Myelosuppression did not occur during treatment. Complete blood counts showed a white blood cell count in the range of 36-69 $\times 10^{2} / \mathrm{l}$, a hemoglobin level range of 8.9-10.2 g/dl, and a platelet count range of $162-265 \times 103 / 1$. No congestive heart failure occurred. Hemodialysis continued three times per week without adverse events. Furthermore, no severe adverse event, including liver functional impairment, intestinal pneumonia, or Stevens-Johnson syndrome occurred. However, mild adverse events including fatigue and edema were observed, and his metastases remained stable for 4 months. Finally, imatinib treatment was discontinued because of progression of the disease and worsening performance status in January 
C 2016 The Author(s). Published by S. Karger AG, Basel www.karger.com/crg

Niikura et al.: Safety of Regular-Dose Imatinib Therapy in Patients with Gastrointestinal Stromal Tumors Undergoing Dialysis

2015. The patient died of duodenal perforation induced by residual tumor progression in February 2015, 6 years after the initial diagnosis and 5 months after chemotherapy for GIST.

\section{Discussion}

We administered regular-dose imatinib in a patient with multiple metastases from GIST undergoing dialysis. The patient remained stable without any adverse event associated with imatinib for 4 months. To our knowledge, this is the first literature review and third case report of imatinib treatment for GIST in patients undergoing dialysis.

Chemotherapy in dialysis patients continues to increase [6]. Several cytotoxic drug therapies have been reported in patients with major gastrointestinal tract malignancies undergoing dialysis. Dialysis patients with esophageal cancer have been administered 5fluorouracil and cisplatin [7-9] and dialysis patients with gastric cancer have been administered tegafur-uracil, docetaxel, and irinotecan [10,13]. Dialysis patients with colon cancer have been treated with tegafur-uracil, irinotecan, and oxaliplatin [14-24]. In these cases, most cytotoxic drugs were used safely without dose modification, but irinotecan caused severe myelosuppression and resulted in death $[15,18]$. Selection of a chemotherapeutic agent is an important issue in dialysis patients. However, available data on molecular-specific therapies in dialysis patients are limited, and treatment-related issues are unclear.

Table 1 lists previous reports of imatinib treatment in patients with GIST undergoing dialysis. Pappas et al. [25] reported a 44-year-old woman with rectal GIST and liver metastasis undergoing dialysis for 1 year. She had undergone surgery for rectal GIST 7 years earlier. Six years later, she was diagnosed with liver metastasis of the resected rectal GIST and received regular-dose imatinib for the liver metastasis. No severe adverse events associated with imatinib occurred, and the liver metastasis remained in partial remission for 12 months. Wada et al. [26] reported a 69-year-old Japanese man with peritoneal GIST undergoing dialysis for 9 years. The main lesion of the peritoneum GIST was resected, and he received regular-dose imatinib for residual disease. No severe adverse event occurred, and the residual disease remained in partial remission for 20 months.

In our case and the previous cases, no severe adverse events were associated with imatinib. Imatinib is metabolized by cytochrome P450 isoenzymes in the gut wall and liver [27]. A previous study evaluated the pharmacokinetics of both imatinib and its metabolite CGP74588 in dialysis patients and reported that the pharmacokinetics of dialysis patients were similar to those of non-dialysis patients [25]. The clinical importance of these data was supported by our results, and we also consider that dialysis patients can be treated safely with imatinib. However, our case showed grade 2 fatigue and grade 2 edema during chemotherapy. These findings have been reported as warning signs of congestive heart failure [28]. Heart failure was not observed in our case due to strict water management, but physicians should pay careful attention to patients with these findings.

Previous studies reported good clinical outcomes, with no recurrence after 12-20 months $[25,26]$. The effects of imatinib are dose-dependent [29]. Imatinib treatment without dose reduction may contribute to good responses in patients undergoing dialysis as well as those without dialysis. In our case, overall survival was shorter than that in previous reports $[25,26]$, but the difference may be due to the clinical stage at the time of initiation of imatinib treatment. Our case had poor prognostic factors, such as a lesion size larger than $11.1 \mathrm{~cm}$, wall invasion, and hepatic metastasis [30]. We consider that early imatinib treatment is important in patients with GIST undergoing dialysis. 
(C) 2016 The Author(s). Published by S. Karger AG, Basel www.karger.com/crg

Niikura et al.: Safety of Regular-Dose Imatinib Therapy in Patients with Gastrointestinal Stromal Tumors Undergoing Dialysis

\section{Conclusions}

In conclusion, regular-dose imatinib was an effective and safe treatment in a patient with GIST undergoing dialysis. We believe that physicians should perform early imatinib treatment without dose reduction.

\section{Statement of Ethics}

There are no ethical conflicts to declare.

\section{Disclosure Statement}

The authors declare no conflicts of interest.

\section{References}

1 Eneman JD, Philips GK: Cancer management in patients with end-stage renal disease. Oncology (Williston Park) 2005;19:1199-1212.

-2 Dematteo RP, Ballman KV, Antonescu CR, Maki RG, Pisters PW, Demetri GD, Blackstein ME, Blanke CD, von Mehren M, Brennan MF, Patel S, McCarter MD, Polikoff JA, Tan BR, Owzar K; American College of Surgeons Oncology Group (ACOSOG) Intergroup Adjuvant GIST Study Team: Adjuvant imatinib mesylate after resection of localised, primary gastrointestinal stromal tumour: a randomised, doubleblind, placebo-controlled trial. Lancet 2009;373:1097-1104.

-3 Naoe H, Kaku E, Ido Y, Gushima R, Maki Y, Saito H, Yokote S, Gushima R, Nonaka K, Hoshida Y, Murao T, Ozaki T, Yokomine K, Tanaka H, Nagahama H, Sakurai K, Tanaka M, Iyama K, Baba H, Sasaki Y: Brain metastasis from gastrointestinal stromal tumor: a case report and review of the literature. Case Rep Gastroenterol 2011;5:583-589.

4 Feki J, Bouzguenda R, Ayedi L, Bradi M, Boudawara T, Daoud J, Frikha M: Bone metastases from gastrointestinal stromal tumor: a case report. Case Rep Oncol Med 2012;509845.

5 Okamura T, Kanda T, Hirota S, Nishimura A, Kawahara M, Nikkuni K: Imatinib therapy for a patient with metastasis of colonic gastrointestinal stromal tumor: report of a case. Clin J Gastroenterol 2013;6:116121.

-6 Maisonneuve P, Agodoa L, Gellert R, Stewart JH, Buccianti G, Lowenfels AB, Wolfe RA, Jones E, Disney AP, Briggs D, McCredie M, Boyle P: Cancer in patients on dialysis for end-stage renal disease: an international collaborative study. Lancet 1999;354:93-99.

7 Rebibou JM, Chauffert B, Dumas M, Mousson C, Bone MC, Tanter Y, Rifle G: Combined chemotherapy and radiotherapy for esophageal carcinoma in a hemodialyzed patient. Long-term survival. Nephron 1996;74:611-612.

8 Okuyama M, Motoyama S, Maruyama K, Ohta H, Tsuchiya N, Oyake J, Ogawa J: Chemotherapy for an esophageal cancer patient undergoing continuous ambulatory peritoneal dialysis for chronic renal failure and measurement of plasma concentration of the drug (in Japanese). Gan To Kagaku Ryoho 2005;32:1029-1032.

-9 Miura T, Hosojima Y, Nakamura J, Yamada S, Nakazawa Y, Ozeki Y, Miura T, Yanagi M, Yamazaki H, Takahashi T: An elderly hemodialytic case of recurrent esophageal cancer given combination chemotherapy with docetaxel and nedaplatin who showed temporal relief of swallowing disturbance (in Japanese). Gan To Kagaku Ryoho 2010;37:883-885.

10 Cho H, Imada T, Masudo K, Doi C, Inaba M, Tokunaga M, Takanashi Y: Combined 5-FU and CDDP in a gastric cancer patient undergoing hemodialysis - pharmacokinetics of 5-FU and CDDP (in Japanese). Gan To Kagaku Ryoho 2000;27:2135-2138.

11 Kawate S, Takeyoshi I, Morishita Y: Pharmacokinetics of paclitaxel in a hemodialysis patient with advanced gastric cancer: a case report. World J Gastroenterol 2006;12:5237-5239.

12 Tomiyama N, Hidaka M, Hidaka H, Kawano Y, Hanada N, Kawaguchi H, Arimori K, Nakamura C: Safety, efficacy and pharmacokinetics of S-1 in a hemodialysis patient with advanced gastric cancer. Cancer Chemother Pharmacol 2010;65:807-809. 
C 2016 The Author(s). Published by S. Karger AG, Basel www.karger.com/crg

Niikura et al.: Safety of Regular-Dose Imatinib Therapy in Patients with Gastrointestinal Stromal Tumors Undergoing Dialysis

13 Saito Y, Shimada K, Ohno Y, Toshima H, Kobayashi K, Miyashita K, Tsuchiya S, Takinishi Y, Miyokawa A, Itoh T, Sakashita A: 5-FU/l-LV therapy is useful for hemodialysis patients with advanced gastric cancer (in Japanese). Gan To Kagaku Ryoho 2011;38:449-451.

14 Akiyama S, Nakayama H, Takami H, Gotoh H, Gotoh Y: Pharmacodynamic study of the Saltz regimen for metastatic colorectal cancer in a hemodialyzed patient. Chemotherapy 2007;53:418-421.

15 Venat-Bouvet L, Saint-Marcoux F, Lagarde C, Peyronnet P, Lebrun-Ly V, Tubiana-Mathieu N: Irinotecanbased chemotherapy in a metastatic colorectal cancer patient under haemodialysis for chronic renal dysfunction: two cases considered. Anticancer Drugs 2007;18:977-980.

-16 Shinozaki E, Mizunuma N, Tanabe M, Chin K, Ota K, Ohkochi N, Hatake K: Induction of CPT-11 in a patient on hemodialysis with metastatic rectal cancer (in Japanese). Gan To Kagaku Ryoho 2005;32:397-399.

17 Okamoto K, Kobayashi M, Maeda H, Takeshita A: A case of stage IV colon cancer effectively treated with tegafur uracil/calcium folinate in a patient on hemodialysis (in Japanese). Gan To Kagaku Ryoho 2012;39:1151-1153.

18 Huang SH, Chao Y, Wu YY, Luo JC, Kao CH, Yen SH, Li CP: Concurrence of UGT1A polymorphism and end-stage renal disease leads to severe toxicities of irinotecan in a patient with metastatic colon cancer. Tumori 2011;97:243-247.

19 Rengelshausen J, Hull WE, Schwenger V, Goggelmann C, Walter-Sack I, Bommer J: Pharmacokinetics of 5 -fluorouracil and its catabolites determined by $19 \mathrm{~F}$ nuclear magnetic resonance spectroscopy for a patient on chronic hemodialysis. Am J Kidney Dis 2002;39:E10.

20 Shitara K, Munakata M, Muto O, Okada R, Mitobe S, Mino M, Ikami I, Sakata Y: Hepatic arterial infusion of oxaliplatin for a patient with hepatic metastases from colon cancer undergoing hemodialysis. Jpn J Clin Oncol 2007;37:540-543.

21 Stemmler J, Weise A, Hacker U, Heinemann V, Schalhorn A: Weekly irinotecan in a patient with metastatic colorectal cancer on hemodialysis due to chronic renal failure. Onkologie 2002;25:60-63. Ohnishi T, Kanoh T, Shiozaki K, Kimura Y, Iwazawa T, Tono T, Nakano Y, Yano K, Mizuno H, Shin S, Monden T: FOLFOX 4 in a patient with metastatic colorectal cancer on hemodialysis due to chronic renal failure (in Japanese). Gan To Kagaku Ryoho 2007;34:1299-1302.

23 Miyazawa T, Chida T, Hasegawa S, Iwafuchi Y, Kamimura A, Watanabe G: A case of sigmoid colon cancer in a patient undergoing hemodialysis treated by tegafur/uracil/folinate (in Japanese). Gan To Kagaku Ryoho 2008;35:149-151.

-24 Sato Y, Doden K, Nishida Y, Shimizu S, Tanaka N, Yagi D, Asaumi Y, Hirano Y, Maeda K, Miyanaga T, Hattori M, Hashizume Y: Bevacizumab therapy for a colorectal cancer patient or hemodialysis with hepatic metastasis (in Japanese). Gan To Kagaku Ryoho 2013;40:647-650.

25 Pappas P, Karavasilis V, Briasoulis E, Pavlidis N, Marselos M: Pharmacokinetics of imatinib mesylate in end stage renal disease. A case study. Cancer Chemother Pharmacol 2005;56:358-360.

26 Wada Y, Ogata H, Misawa S, Shimada A, Kinugasa E: A hemodialysis patient with primary extragastrointestinal stromal tumor: favorable outcome with imatinib mesylate. Intern Med 2012;51:15611565.

27 de Kogel CE, Schellens JH: Imatinib. Oncologist 2007;12:1390-1394.

-28 Mant J, Doust J, Roalfe A, Barton P, Cowie MR, Glasziou P, Mant D, McManus RJ, Holder R, Deeks J, Fletcher K, Qume M, Sohanpal S, Sanders S, Hobbs FD: Systematic review and individual patient data meta-analysis of diagnosis of heart failure, with modelling of implications of different diagnostic strategies in primary care. Health Technol Assess 2009;13:1-207.

29 Verweij J, Casali PG, Zalcberg J, LeCesne A, Reichardt P, Blay JY, Issels R, van Oosterom A, Hogendoorn PC, Van Glabbeke M, Bertulli R, Judson I: Progression-free survival in gastrointestinal stromal tumours with high-dose imatinib: randomised trial. Lancet 2004;364:1127-1134.

-30 Tateishi U, Hasegawa T, Satake M, Moriyama N: Gastrointestinal stromal tumor. Correlation of computed tomography findings with tumor grade and mortality. J Comput Assist Tomogr 2003;27:792798.

-31 Eisenhauer EA, Therasse P, Bogaerts J, Schwartz LH, Sargent D, Ford R, Dancey J, Arbuck S, Gwyther S, Mooney M, Rubinstein L, Shankar L, Dodd L, Kaplan R, Lacombe D, Verweij J: New response evaluation criteria in solid tumours: revised RECIST guideline (version 1.1). Eur J Cancer 2009;45:228-247. 


\section{Case Reports in \\ Gastroenterology}

\begin{tabular}{l|l}
\hline Case Rep Gastroenterol 2016:10:17-23 \\
\hline & $\begin{array}{l}\text { C } 2016 \text { The Author(s). Published by S. Karger AG, Basel } \\
\text { www.karger.com/crg }\end{array}$ \\
\hline
\end{tabular}

Niikura et al.: Safety of Regular-Dose Imatinib Therapy in Patients with Gastrointestinal Stromal Tumors Undergoing Dialysis


Fig. 1. The resected tumor: composed of spindle-shaped cells, hematoxylin and eosin stain, $\times 20$ (a); positive for KIT, $\times 20$ (b); positive for CD34, $\times 20$ (c); negative for S-100, $\times 20$ (d); and with a MIB-1 labeling index of $10 \%, \times 20(\mathbf{e})$. 
 Gastroenterology}

Niikura et al.: Safety of Regular-Dose Imatinib Therapy in Patients with Gastrointestinal Stromal Tumors Undergoing Dialysis

Table 1. Review of the literature on imatinib treatment in patients with GIST undergoing dialysis

\begin{tabular}{llll}
\hline & Our case & Case 1 & Case 2 \\
\hline First author [Ref.] & Niikura & Pappas [25] & Wada [26] \\
Patient & 75 -year-old man & 44 -year-old woman & 69-year-old man \\
Hemodialysis period, years & 0.8 & 1 & 9 \\
Tumor location & Duodenum & Rectum & Peritoneum \\
Tumor size, cm & 14.5 & Not reported & 11.2 \\
Staging & Multiple liver and bone metastases & Multiple liver metastases & No metastasis \\
Imatinib dose, mg/day & 400 & 400 & 400 \\
Timing of administration & After hemodialysis & Not reported & Not reported \\
Response [31] & Stable disease & Partial response & Partial response \\
Overall survival, months & 5 & Not reported & Not reported \\
Adverse events & Grade 2 fatigue and grade 2 edema & No major adverse events & No major adverse events \\
\hline
\end{tabular}

${ }^{1}$ Adverse events of imatinib treatment were evaluated using the Japan Clinical Oncology Group Common Terminology Criteria for Adverse Events version 4.0, Japan Clinical Oncology Group (http://www.jcog.jp/doctor/tool/ctcaev4.html, accessed July 29, 2013). ALT = Alanine aminotransferase; $\mathrm{AST}=$ aspartate aminotransferase. 